cancers caused by the atom bombs dropped on Japan and to assume that there is a linear dose-to-risk relation from colossal doses of 100 rems or more delivered in a fraction of a second to doses of a few rems delivered over decades. Bodansky et al. is the only book to consider this linearity hypothesis at length, and to point out the unlikelihood of linearity over such a range of dose and dose rate. However, the probable exaggeration of low-level risks gives me confidence that the legal limits based on the ICRP assumptions (100 millirems per year for the public) are not set too high.

In all the books, there is lengthy discussion of the alternative method of risk estimation by using the records of the excess cancer rates in uranium miners before the dangers of inhalation had been realized. The results are complicated because a large but unknown proportion of the miners were cigarette smokers. The cancer rate among white miners was much higher than that expected of cigarette smokers in general; but, as is explained in all the books except Cothern and Smith's, which quotes conflicting reports, the cancer rates from smoking and from inhaling radon progeny are likely to have a synergistic interaction.

In Bodansky et al., Hopke and BEIR IV, there is mention that a group of Navaho Indian miners, few of whom smoked, also suffered extra lung cancers. But the smaller numbers involved, and the uncertainty of the dose received, prevent any reliable estimates of the risk to nonsmokers - except that there is a risk to non-smokers.

The results of the study of the uranium miners are less definite than might be expected. In the summary of his contribution to Hopke's book, Steinhäusler says:

Available input data for the risk assessment for low level radon daughter $(\mathrm{Rn}-\mathrm{d})$ exposure are mostly either of low quality, partially contradictory, or simply "guesstimates". Therefore at present only the upper limit of the risk can be estimated. ... It is concluded that for "normal" indoor Rn-d exposure the resulting risk is negligible compared to other risks "accepted" by society.

In his longer and later article in Nazaroff and Nero, he expresses the same point in a different way: on the basis of the data on uranium miners, the most probable risk is ten per million person years per rem, $\pm 100 \%$.

In estimating risks, there is also the question of differences of susceptibility among the populations exposed. Risks may be absolute (a given dose will add the same extra risk to everyone of a given age) or relative (the extra risk will be proportional to the pre-existing risk of lung cancer due to other causes). Data for average populations can be made to fit either hypothesis. A relative risk would imply

\section{Grub's up}

\section{John Treherne}

Why Not Eat Insects? By Vincent M. Holt British Museum (Natural History)/E.W. Classey: 1885/1988. Pp. 99. Pbk £3.95. In the United States available from ISBS, 5602 NE Hassalow St, Portland, Oregon $97213, \$ 7.95$.

WHEN I was a child, a rather fierce relative used to boast that he ate locusts during the Matabele Rebellion (or it may have been the Boer War, I forget which). They tasted very nice, he said: like shrimps, when they were cooked properly.

Uncle Dennis had to eat the beastly things or he would have starved. And that is the odd thing about Mr Holt's little book, for there is no indication of why he actually started to eat insects. Did the other boys make him do it at school? Or did he survive on them in the Gobi Desert and then found it difficult to kick the habit? We are never told. But we are given cogent reasons why we should tuck into the Insecta. There are the poor, for example. A great boon for them in 1885 , when Mr Holt originally penned his study, as well as, presumably, for their modern equivalents, teetering on the verge of malnutrition with junk food. As Mr Holt

that cigarette smokers, who have a ten times larger risk, in Europe and the United States, of contracting lung cancer than have non-smokers, will also suffer a ten times larger excess for the same dose from the radon progeny. This possibility is discussed in all of the books except that edited by Hopke. BEIR IV comes down in favour of the relative risk model, and is likely to be right, but one cannot yet be convinced of that.

All of the books, except BEIR IV, include descriptions of varying length of the means by which radon doses can be reduced. For new buildings, sealing the foundations, including the entry points of service pipes, or provision of a wellventilated crawl space below the ground floor, will be effective and involve no subsequent costs. For existing buildings, too much depends on the type of structure, its heating system and the way of life of its inhabitants to give generally useful recommendations. Keeping the windows open all the year round and wearing extra clothes can be very effective if (as at my age, I do not) you prefer cold to radon.

All the books are commendably free of printing errors, but the references have the serious disadvantage of being listed chapter by chapter - an infuriating practice. As usual, a variety of units are used: rads and rems, grays and sieverts, and points out, what a pleasant change from the labourer's unvarying diet - in his day, of bread and lard and bacon - would be a good dish of fried cockchafers or grasshoppers. And, in so varying the monotony of their diet, the poor would unwittingly assist agricultural pest control. No need to wash the vegetables either, for what could be nicer than cabbage served up with a delicately flavoured fringe of caterpillars?

But it is to gourmets that Mr Holt primarily appeals. After all, they have been guzzling the Invertebrata more than most - snails, lobsters, oysters and the like and just might be tempted by stag beetle larvae on toast or new carrots with wireworm sauce or gooseberry cream with sawflies. Yet Mr Holt's ideas seem to have made little impact on the society of Oscar Wilde and Mr Gladstone. They might fare better in Mrs Thatcher's Britain though. Not with her poor either, I suspect, but it is just conceivable that the jaded palate of the upwardly affluent might be tickled by Larves de Guêpes Frites au Rayon or Boeuf aux Chenilles - and could even lead to the setting up of the odd entomological brasserie in Kensington or Holland Park.

John Treherne is a Fellow of Downing College, Cambridge CB2 1DO, UK, and Honorary Director of the AFRC Unit of Insect Neurophysiology and Pharmacology, Department of Zoology, University of Cambridge.

working level months (WLMs). It is a great pity that the inconveniently large gray and sievert were ever invented, but the incommensurable WLMs met a real need. I have throughout translated all units into rems, counting 1 WLM as $1 \mathrm{rem}$; the error involved is small compared to the uncertainties in the data for which it was used.

The message of these five books is that a great deal of research has produced little evidence to support or to weaken the estimates of risk made by the ICRP. It has, however, confirmed that the radiation doses from radon exceed by a factor of many hundreds those arising from the nuclear power industry - hence my puzzlement over why the public bothers so little about the health risks of radon.

It will take a different type of publication to get that point through to the public. For professionals, each of the volumes reviewed here says something better than do the other four. For myself, I prefer that edited by Bodansky et al., the only one to compare the dangers of radon and its progeny with other radiation hazards, and which presents its information in the most succinct and digestible form.

John Fremlin, 46 Vernon Road, Edgbaston Birmingham B16 9SH, UK, is Professor Emeritus of Applied Radioactivity in the University of Birmingham. 